\title{
Influencing Factor Sensitivity Analysis of Dynamic Loading of the Projectile Engraving Experimental Facility
}

\author{
Xue-long Cao ${ }^{1,}$, Jun-qi Qin ${ }^{1}$, Chang-chun $\mathrm{Di}^{1}$ and Ye-zun Sun ${ }^{2, b}$ \\ ${ }^{1}$ Ordnance Engineering College, Shijiazhuang 050003, China; \\ ${ }^{2}$ Beijing Military Delegation Office Located at Fact.247, Taiyuan 030009, China. \\ ahokloong@sina.com, bsunyezun@163.com
}

Keywords: sensitivity, dynamic loading, engraving process, experimental facility

\begin{abstract}
In combination with one projectile engraving experimental facility, movement role of the facility and work principle of its parts are analyzed. And structural parameters are considered to have the most influence on the dynamic loading. A virtual prototype model is established by ADAMS (Automatic Dynamic Analysis of Mechanical System) to analyze how the structural parameters of the system affect regulation spring force and projectile velocity. By designing variable parameters, the sensitivity of each factor is obtained. And an optimized method is put forward to design the projectile engraving experimental facility in actual conditions.
\end{abstract}

\section{Introduction}

After the completion of ignition and flame spreading in shooting process of the gun, a large amount of gunpowder combustion with high temperature and high pressure gas push the projectile to move. Since the diameter of the rotating band is slightly larger than that of the shade line of inner bore, the rotating band is deformed and forced into the bore. While the whole rotating band engraves, responding gunpowder pressure is called engraving pressure, that process is called engraving process. Engraving process is the initial stage of the interior ballistics. And engraving pressure is related to the structure characteristic of the rotating band, length of the chamber throat and the powder charge. Based on the nonlinear finite method and dynamic simulation, the deformation of the rotating band is obtained, and many researchers come up with the test method and relating calculation means of engraving pressure[1-3]. A fitted curve is calculated to force on the bottom of projectile as gunpowder combustion pressure. Since live weapon firing consume much funds, meanwhile the efficiency of this way is poor. So how to simulate gunpowder combustion pressure in laboratory become important. Before a lot of experimental facility are developed, press machine is used to force projectile into the rifling in quasi-static condition. Through testing the pressure that projectile suffer, a curve reflecting the projectile engraving resistance is obtained. Instantly, with the development of the light gas gun[4, 5], Hopkinson pressure bar[6], spring pusher[7], and other test facilities, the effect of propellant on the projectile is simulated in mechanical ways.

In order to study the projectile engraving process, based on the spring pusher experimental facility, the dynamic loading forced on the bottom of the projectile is simulated by ADAMS. The feasibility using mechanical method to simulate propellant pressure is analyzed. And an optimized method is put forward to design the projectile engraving experimental facility in actual conditions.

\section{Spring pusher facility movement analysis and modeling}

Motion Analysis. Since the direct use of motor driven require a motor possesses higher performance. And the impact feedback that the motor suffers during test and operation is high, it causes the reliability of the system gradually drop off. Because motor driving springs and then the spring store energy while using spring pusher facility, fast release of spring energy makes for the simulating dynamic loading and protects the system. In the improved experimental facility, a motor is used to driven the pusher mechanism of the projectile engraving experimental facility, and the push 
rod impact on the bottom of the projectile so that the rotating band deforms and projectile engraves into the rifling. System contains facility substrate, clamping mechanism, loading spring, mass block, baffle, regulation spring, and push rod, projectile. Fig. 1 shows the structure of simplified experimental facility.

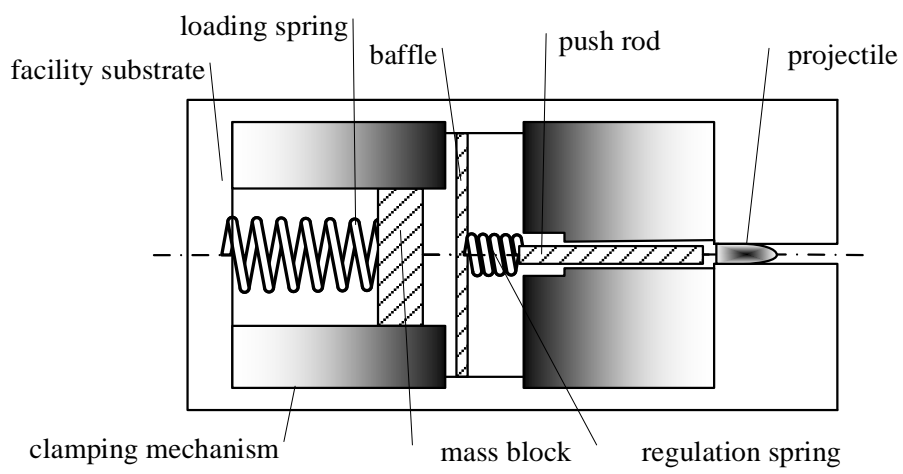

Fig. 1 Structure of simplified experimental facility

Through releasing the energy that loading spring stores while system works, mass block impacts baffle. The impact force is transferred to oscillating force by regulation spring so that the effect is close to the propellant pressure. Finally the projectile is pushed by the push rod and engraves into rifling.

Modeling. Considering the impact action as an mass- spring system without damp, the stiffness is defined as steel to steel, equals $10^{5} \mathrm{~N} / \mathrm{mm}$. While the mass of spring is not considered or calculate the spring mass into the mass of block. The spring pusher facility can be simplified into four degree of freedom mass-spring system. Fig. 2 shows four degree of freedom mass-spring system.

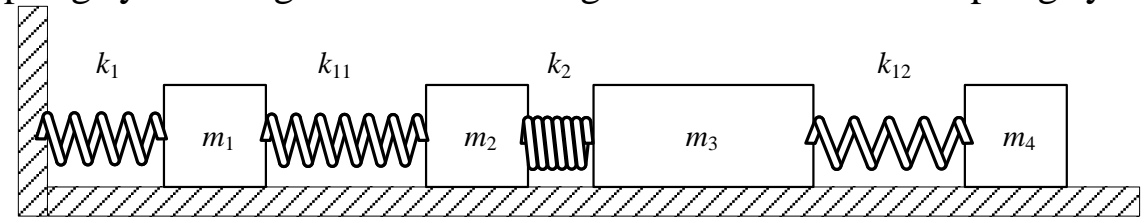

Fig. 2 Four degree of freedom mass-spring system.

In Fig. 2, $m_{1} \sim m_{4}$ is respectively the simplified mass of mass block, baffle, push rod, and projectile, $k_{1}$ means loading spring stiffness, $k_{2}$ means regulation stiffness, $k_{11}$ means the stiffness of the impact effect between mass block and baffle, $k_{12}$ means the stiffness of the impact effect between push rod and projectile. Table 1 shows parameter of mass and spring and their value[8].

Table 1 Parameter of mass and spring

\begin{tabular}{cccccccc}
\hline$k_{1}$ & $k_{11}$ & $k_{2}$ & $k_{12}$ & $m_{1}$ & $m_{2}$ & $m_{3}$ & $m_{4}$ \\
\hline $1000 \mathrm{~N} / \mathrm{m}$ & $10^{5} \mathrm{~N} / \mathrm{m}$ & $5000 \mathrm{~N} / \mathrm{m}$ & $10^{5} \mathrm{~N} / \mathrm{m}$ & $50 \mathrm{~kg}$ & $4 \mathrm{~kg}$ & $20 \mathrm{~kg}$ & $30 \mathrm{~kg}$ \\
\hline
\end{tabular}

Choosing generalized coordinates $x_{1} \sim x_{4}$, based on Lagrange's equation, the system equation of motion is established. System kinetic energy equation is

$$
T=\frac{1}{2} \sum_{i=1}^{4} m_{i} \dot{x}_{i}^{2} .
$$

Potential energy equation is

$U=\frac{1}{2} k_{1} x_{1}^{2}+\frac{1}{2} k_{11}\left(x_{2}-x_{1}\right)^{2}+\frac{1}{2} k_{2}\left(x_{3}-x_{2}\right)^{2}+\frac{1}{2} k_{12} x_{4}^{2}$.

Substituting $T$ and $U$ into Lagrange's equation, and we get

$M \ddot{x}+K x=0$.

Among them, the quality matrix is 


$$
[M]=\left[\begin{array}{cccc}
50 & 0 & 0 & 0 \\
0 & 4 & 0 & 0 \\
0 & 0 & 20 & 0 \\
0 & 0 & 0 & 30
\end{array}\right]
$$

The stiffness matrix is

$$
[K]=\left[\begin{array}{cccc}
1000+10^{5} & -10^{5} & 0 & 0 \\
-10^{5} & 10^{5}+5000 & -5000 & 0 \\
0 & -5000 & 5000+10^{5} & -10^{5} \\
0 & 0 & -10^{5} & 10^{5}
\end{array}\right]
$$

Then the free vibration differential equation is

$$
\left[\begin{array}{cccc}
50 & 0 & 0 & 0 \\
0 & 4 & 0 & 0 \\
0 & 0 & 20 & 0 \\
0 & 0 & 0 & 30
\end{array}\right]\left[\begin{array}{l}
\ddot{x}_{1} \\
\ddot{x}_{2} \\
\ddot{x}_{3} \\
\ddot{x}_{4}
\end{array}\right]+\left[\begin{array}{cccc}
1000+10^{5} & -10^{5} & 0 & 0 \\
-10^{5} & 10^{5}+5000 & -5000 & 0 \\
0 & -5000 & 5000+10^{5} & -10^{5} \\
0 & 0 & -10^{5} & 10^{5}
\end{array}\right]\left[\begin{array}{l}
x_{1} \\
x_{2} \\
x_{3} \\
x_{4}
\end{array}\right]=0
$$

Supposing its solution is $x_{i}=A_{i} \sin \left(\omega_{n} t+\varphi\right)$, based on MATLAB program, system inherent frequencies are calculated as follows: $\omega_{n 1}=164 \mathrm{rad} / \mathrm{s}, \omega_{n 2}=91 \mathrm{rad} / \mathrm{s}, \omega_{n 3}=10 \mathrm{rad} / \mathrm{s}$, $\omega_{n 4}=10 \mathrm{i} \mathrm{rad} / \mathrm{s}$. The corresponding main modes are:

$$
\left\{A_{1}\right\}=\left\{\begin{array}{c}
0.1811 \\
-2.2542 \\
-0.2026 \\
1.0000
\end{array}\right\} \quad\left\{A_{2}\right\}=\left\{\begin{array}{c}
0.0245 \\
-0.0769 \\
-1.5181 \\
1.0000
\end{array}\right\} \quad, \quad\left\{A_{3}\right\}=\left\{\begin{array}{c}
-0.9075 \\
-0.8621 \\
0.9764 \\
1.0000
\end{array}\right\} \quad\left\{A_{4}\right\}=\left\{\begin{array}{l}
0.9495 \\
0.9970 \\
1.0293 \\
1.0000
\end{array}\right\}
$$

The preload length of loading spring is $s_{1}=400 \mathrm{~mm}$, the initial distance between loading spring and baffle is $s_{2}=300 \mathrm{~mm}$. Then a spring pusher facility model is established by ADAMS. Fig. 3 shows the virtual prototype model.

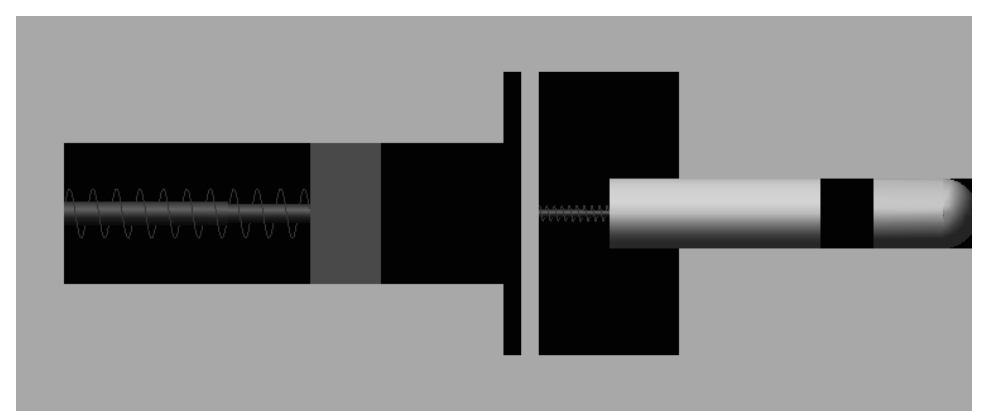

Fig. 3 Virtual prototype model of the spring pusher facility

\section{Simulation and Sensitivity analysis}

Simulation results. Setting simulation time equals $0.03 \mathrm{~s}$ before calculation, the curve of regulation spring force and projectile velocity is obtained shows in Fig. 4. 

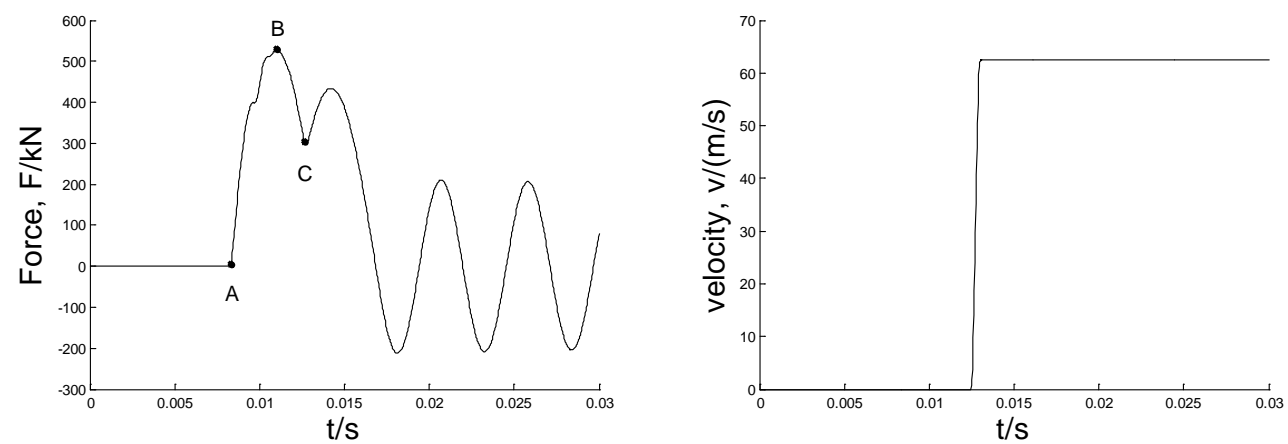

Fig. 4 The curve of regulation spring force and projectile velocity

According to the curve of regulation spring, regulation spring suffers the impact from the baffle, the maximum force equals $530 \mathrm{kN}$ at point $\mathrm{B}$, amount to $53.0 \mathrm{t}$ mass force. In the impact process, the baffle impacts mass block while $t=0.0094 \mathrm{~s}$ at point A. It causes force oscillation of regulation spring. While $t=0.0123 \mathrm{~s}$ at ponit $\mathrm{C}$, regulation spring force push rod to impact projectile. The vecocity of projectile can reach $62.44 \mathrm{~m} / \mathrm{s}$.

Sensitivity analysis. Revising the value of each parameter, the force of regulation spring is considered as an objective function. Parameters $k_{1}, k_{2}, m_{1}, m_{2}, m_{3}, m_{4}$ are defined as design variables that respectively are $\mathrm{DV}_{1}, \mathrm{DV}_{2}, \mathrm{DV}_{3}, \mathrm{DV}_{4}, \mathrm{DV}_{5}, \mathrm{DV}_{6}$. In order to assess the sensitivity of each parameter, six tests are conducted for five levels. The test curves show in Fig. 5.
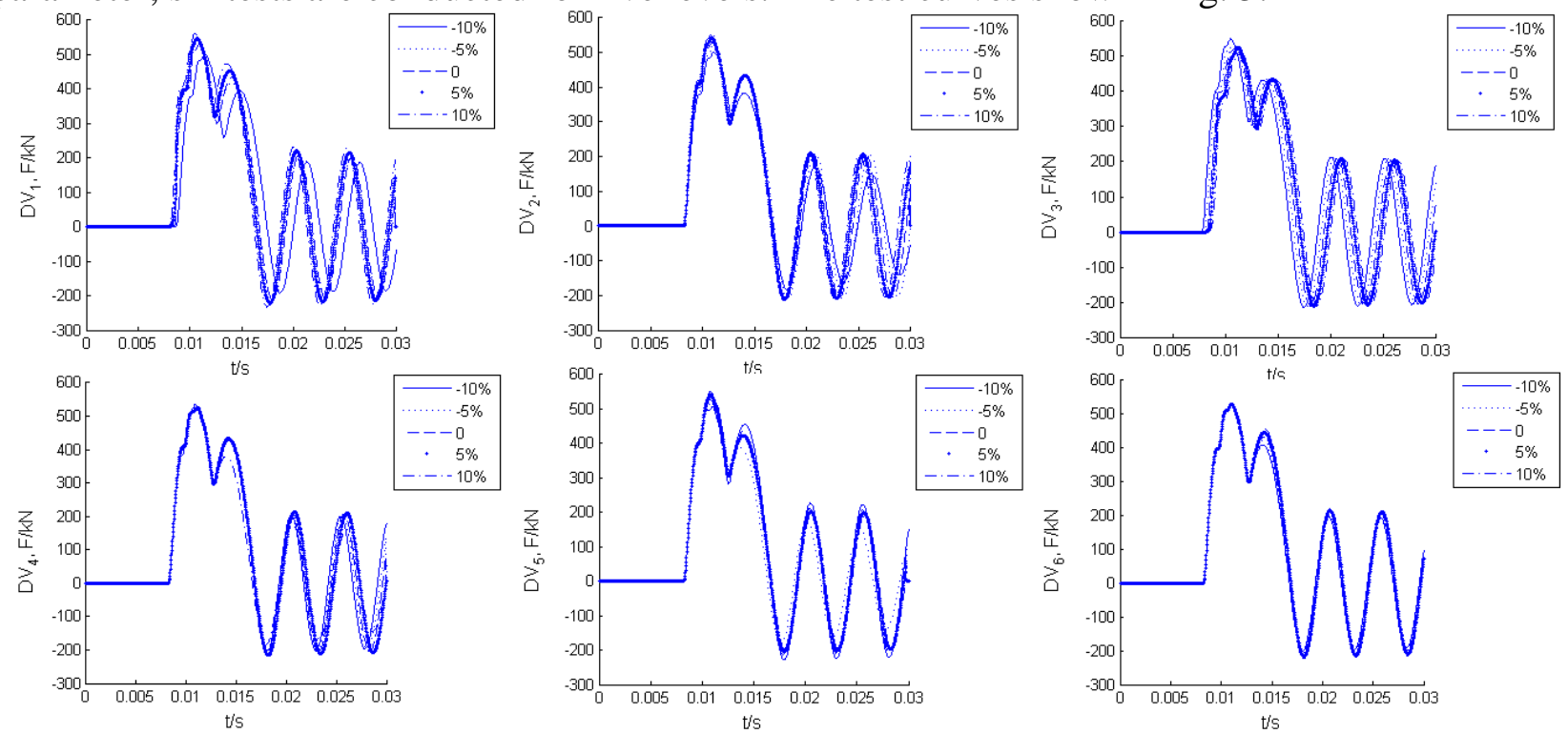

Fig. 5 Sensitivity curves of design variable

The initial sensitivity of each variable shows in Table 2.

Table 2 Parameter of mass and spring

\begin{tabular}{cccccc}
\hline $\mathrm{DV}_{1}$ & $\mathrm{DV}_{2}$ & $\mathrm{DV}_{3}$ & $\mathrm{DV}_{4}$ & $\mathrm{DV}_{5}$ & $\mathrm{DV}_{6}$ \\
\hline 51.7 & 5.6 & -220.9 & -16841.0 & -9863.3 & 802.3 \\
\hline
\end{tabular}

Sensitivity analysis shows that baffle mass has more influence on the force of regulation spring than other parameters, and push rod secondly. The front end of baffle suffers the impact of loading mass block, and the after end of that connects a regulation spring with high stiffness so that the movement of baffle is complex. The mass of baffle is small, and the contact area with block is large, so there exists stability problem and loading osillation. It may be a vulnerable spot of the system. Combining the sensitivity analysis for the force in regulation spring, it shows a part with small mass influence more and a large part effect less. Contrasting spring parts and mass parts, it shows that the regulation spring force is more sensitive to mass parameters. So in the process of designing spring pusher facility, after selecting springs possess appropriate stiffness, it should place extra emphasis on the mass of every part, especially the part whose contact area with others is large. 


\section{Summary}

In the present work, the influencing factor sensitivity analysis of dynamic loading was studied in simplified system. The main conclusions are summarized below:

(1)Virtual prototyping technology can simulate the movement of complicated mechanism such as spring pusher facility well. Through motion analysis, it shows that the system possesses four inherent frequencies and four corresponding main modes. When designing the facility, the excited frequency of dynamic loading should diverge from the natural frequency to avoid resonance.

(2) Under the existing condition, the force of regulation spring can reach an ideal value then the force can transfer to a dynamic loading forced on the bottom of projectile. The force oscillation enhances the system reliability but may cause a second contact between mass block and baffle.

(3)Under actual conditions, mass property of each part should be considered for greater dynamic loading before system design, especially the part whose contact area is large.

\section{References}

[1] H.Y. Sun, J.S. Ma, W. Li, Study on influence of different bore structures on engraving process of

projectile. Journal of Vibration and Shock, 30(03), (2011), 30-33.

[2] L.C. Mi, S.Z. Gao, C.Y. Lai, The simulation study on band edging properties in interior ballistics.

Journal of Projectiles, Rockets, Missiles and Guidance, 32(01), (2012), 133-135.

[3] M.D. Ma, W.S. Cui, Z.Y. Zeng, Dynamic response analysis of chamber throat in the engraving process

of heavy caliber gun projectile. Journal of North University of China (Natural Science Edition),35(03), (2014), 263-269.

[4] J. Huang, S.C. Liang, H.Y. Li, S. Liu, Numerical research on interior ballistics of the launch process of

two-stage light gas gun. Acta Aerodynamic Sinica, 31(05), (2013), 657-661.

[5] A. Sabet, N. Fagih, M.H. Beheshty. Effect of reinforcement type on high velocity impact response of

GRP plates using a sharp tip projectile. International Journal of Impact Engineering, , 38, (2011), 715-722.

[6] B. Wu, J. Zheng, Q.T. Tian, Z.Z. Qiang, X.H. Yu, Tribology of rotating band and gun barrel during

engraving process under quasi-static and dynamic loading. Friction, 2(4), (2014), 330-342.

[7] Q. Zheng. Analysis of the operating characteristics of the projectile pushing simulation testing system.

Nanjing: Nanjing University of Science and Technology, (2012).

[8] G. Lin. Simulatin on experimental facility design of the rotating band engraving process. Nanjing:

Nanjing University of Science and Technology, (2014). 